\title{
Dietary fibre intake and the risk of diverticular disease: a systematic review and meta-analysis of prospective studies
}

\author{
Dagfinn Aune ${ }^{1,2,3} \cdot$ Abhijit Sen $^{4} \cdot$ Teresa Norat $^{1} \cdot$ Elio Riboli $^{1}$
}

Received: 20 September 2018 / Accepted: 8 April 2019 / Published online: 29 April 2019

(c) The Author(s) 2019

\begin{abstract}
Background A high intake of dietary fibre has been associated with a reduced risk of diverticular disease in several studies; however, the dose-response relationship between fibre intake and diverticular disease risk has varied, and the available studies have not been summarised in a meta-analysis. We conducted a systematic review and meta-analysis of prospective cohort studies to clarify the association between dietary fibre intake, fibre subtypes, and the risk of diverticular disease.

Methods PubMed and Embase databases were searched up to August 9th 2018. Summary relative risks (RRs) and 95\% confidence intervals (CIs) were calculated using a random-effects model and nonlinear associations were modelled using fractional polynomial models.

Results Five prospective cohort studies with 19,282 cases and 865,829 participants were included in the analysis of dietary fibre and diverticular disease risk. The summary RR was 0.74 (95\% CI $\left.0.71-0.78, I^{2}=0 \%\right)$ per $10 \mathrm{~g} /$ day. There was no evidence of a nonlinear association between dietary fibre intake and diverticular disease risk, $p_{\text {nonlinearity }}=0.35$, and there was a $23 \%, 41 \%$ and $58 \%$ reduction in risk for an intake of 20,30 , and $40 \mathrm{~g} /$ day, respectively, compared to $7.5 \mathrm{~g} /$ day. There was no evidence of publication bias with Egger's test, $p=0.58$ and the association persisted in subgroup and sensitivity analyses. The summary RR per $10 \mathrm{~g}$ /day was $0.74\left(95 \%\right.$ CI $\left.0.67-0.81, I^{2}=60 \%, n=4\right)$ for cereal fibre, $0.56\left(95 \%\right.$ CI $0.37-0.84, I^{2}=73 \%$, $n=2)$ for fruit fibre, and 0.80 (95\% CI $\left.0.45-1.44, I^{2}=87 \%, n=2\right)$ for vegetable fibre.

Conclusions These results suggest that a high fibre intake may reduce the risk of diverticular disease and individuals consuming $30 \mathrm{~g}$ of fibre per day have a $41 \%$ reduction in risk compared to persons with a low fibre intake. Further studies are needed on fibre types and risk of diverticular disease and diverticulitis.
\end{abstract}

Keywords Fibre $\cdot$ Diverticular disease $\cdot$ Systematic review $\cdot$ Meta-analysis

Electronic supplementary material The online version of this article (https://doi.org/10.1007/s00394-019-01967-w) contains supplementary material, which is available to authorized users.

Dagfinn Aune

d.aune@imperial.ac.uk

1 Department of Epidemiology and Biostatistics, School of Public Health, Imperial College London, St. Mary's Campus, Norfolk Place, Paddington, London W2 1PG, UK

2 Department of Nutrition, Bjørknes University College, Oslo, Norway

3 Department of Endocrinology, Morbid Obesity and Preventive Medicine, Oslo University Hospital, Oslo, Norway

4 Department of Public Health and Nursing, Faculty of Medicine and Health Sciences, Norwegian University of Science and Technology, Trondheim, Norway

\section{Introduction}

Diverticular disease has been considered a "disease of the western civilisation" [1] due to the fact that the incidence and prevalence of diverticular disease range more than 20-40-fold between high- and low-risk populations, and tend to be more common in high-income countries, where Westernised lifestyles prevail, than in low-income countries $[2,3]$. Secular trend studies have found rapid increases in the incidence of diverticular disease within countries, with rates increasing two- to fourfold between 1974 and 1986 in Japan [4]. An autopsy study reported a prevalence of $1 \%$ among Japanese in Japan, but a prevalence of 50\% among Japanese in the US [5]. In addition, other migration studies have also suggested an increased risk with a longer duration since settlement [6]. In the US, $65 \%$ of adults will develop diverticulosis by age 80 years $[7,8]$. Collectively, these observations 
suggest that modifiable risk factors are of major importance for the development of diverticular disease. Overweight and obesity [9], low physical activity [9], smoking [10] and NSAID use [11] are established risk factors for diverticular disease.

A diet low in fibre and high in red meat has been associated with increased risk of diverticular disease [12] as well as other diseases of the colon including colorectal adenomas [13], colorectal cancer [14] and Crohn's disease [15]. Several prospective studies have consistently reported a lower risk of diverticular disease with a high fibre intake [12, 16-18]; however, the shape of the dose-response relationship has differed somewhat with some studies reporting a clear dose-response relationship with increasing benefit with higher fibre intake $[12,16,17]$, while in two studies (one publication) there was no further benefit at very high intakes [18]. Data are also not entirely consistent with regard to the types of fibre that may be beneficial. In the Health Professionals Follow-up Study, there was an inverse association between fibre from fruit and vegetables, and risk of diverticular disease, but no association was observed for cereal fibre [12]. In the Million Women's Study, there was an inverse association for fibre from fruits, vegetables, and cereals, but a positive association was observed with intake of fibre from potatoes; however, after mutual adjustment between fibre types, the inverse association with vegetable fibre disappeared [17]. In the Swedish Mammography Cohort and the Cohort of Swedish Men, fibre from fruit and vegetables were inversely associated with diverticular disease risk, but no significant association was observed with fibre from cereals [18]. To provide a better estimate of the strength and shape of the dose-response relationship between intakes of fibre and subtypes of fibre and diverticular disease risk, we therefore conducted a systematic review and meta-analysis of published prospective studies on fibre intake and risk of diverticular disease.

\section{Methods}

\section{Search strategy and inclusion criteria}

We (DA, AS) searched the PubMed, and Embase databases from inception up to August 9th 2018 for eligible studies as part of a larger project on risk factors for diverticular disease. The search terms used are found in the Supplementary Text. We followed standard criteria (Moose) for reporting meta-analyses [19]. In addition, we searched the reference lists of the identified publications for further studies.

\section{Study selection}

We included published prospective cohort studies and nested case-control studies within cohorts that investigated the association between dietary fibre intake and diverticular disease risk. Adjusted estimates of the relative risk (RR) had to be available with the $95 \%$ CIs in the publication. Grey literature such as abstracts and unpublished studies were not included. A list of the excluded studies and reasons for exclusions can be found in Supplementary Table 1. DA screened PubMed and AS screened Embase, and both authors screened the 39 potentially relevant studies for final inclusion.

\section{Data extraction}

The following data were extracted from each study: the first author's last name, publication year, country where the study was conducted, study period, sample size, number of cases and participants, exposure, quantity of intake, RRs and 95\% CIs, and variables adjusted for in the analysis. Data were extracted by one author (DA) and checked for accuracy by a second author (AS).

\section{Statistical methods}

We calculated summary RRs (95\% CIs) of diverticular disease by intake of dietary fibre using the random-effects model by DerSimonian and Laird [20] which takes into account both within- and between-study variation (heterogeneity). The average of the natural logarithm of the RRs was estimated and the RR from each study was weighted using random-effects weights [20]. Linear dose-response analyses were conducted using the method of Greenland and Longnecker [21] and study-specific linear trends and 95\% CIs were computed from the natural log of the RRs and CIs across categories of fibre intake per day. The linear dose-response analysis was conducted on a continuous scale with an increment of $10 \mathrm{~g} /$ day. A potential nonlinear association was investigated using fractional polynomial models [22] and we determined the best fitting second order fractional polynomial regression model, defined as the one with the lowest deviance. A likelihood ratio test was used to test for nonlinearity [23].

Heterogeneity between studies was evaluated using $Q$ and $I^{2}$ statistics [24]. $I^{2}$ is a measure of how much of the heterogeneity that is due to between-study variation rather than chance. $I^{2}$ values of $25 \%, 50 \%$ and $75 \%$ indicates low, moderate and high heterogeneity, respectively. We conducted main analyses (all studies combined) and stratified by study characteristics such as duration of follow-up, sex, 
sample size, number of cases, geographic location, study quality and by adjustment for confounding factors to investigate potential sources of heterogeneity. Study quality was assessed using the Newcastle-Ottawa scale which rates studies according to selection, comparability and outcome assessment with a score range from 0 to 9 [25]. In sensitivity analyses, we also repeated the analyses using fixed-effects models. We calculated $95 \%$ prediction intervals (95\% PIs) for the random-effects analyses. The 95\% PIs further account for heterogeneity and show the range in which $95 \%$ of future studies will lie.

Publication bias was assessed using Egger's test [26] and Begg-Mazumdar's test [27] and by inspection of funnel plots. The statistical analyses were conducted using the software package Stata, version 13.1 software (StataCorp, Texas, US).

\section{Results}

We identified five cohort studies (four publications) [12, 16-18], that could be included in the meta-analysis of dietary fibre intake and diverticular disease (Fig. 1, Table 1). Only one study reported on dietary fibre intake and risk of diverticulitis [28] and a meta-analysis was, therefore, not possible on this outcome (Table 1). Four studies were from Europe and one study was from the USA.

Five cohort studies [12,16-18] with 19,282 cases and 865,829 participants were included in the analysis of dietary fibre intake and diverticular disease. The summary RR $(95 \% \mathrm{CI})$ per $10 \mathrm{~g} /$ day was $0.74\left(95 \% \mathrm{CI} 0.71-0.78, I^{2}=0 \%\right.$, $p_{\text {heterogeneity }}=0.80$ ) (Fig. 2a). In sensitivity analyses excluding one study at a time, the summary RR ranged from 0.74 (95\% CI 0.71-0.77) when excluding the Swedish Mammography Cohort [18] to 0.76 (95\% CI 0.69-0.83) when excluding the Million Women's Study [17] (Supplementary Fig. 1). The 95\% PI also excluded the null value, summary RR 0.74 (95\% PI 0.70-0.80). There was no evidence of publication bias with Egger's test $(p=0.58)$, Begg's test $(p=0.81)$ or by inspection of the funnel plots (Supplementary Fig. 2). There was no evidence of a nonlinear association between dietary fibre intake and diverticular disease risk $\left(p_{\text {nonlinearity }}=0.35\right)$, and the summary RRs were 0.77 (95\% CI 0.74-0.79), 0.59 (95\% CI $0.55-0.64)$ and 0.42 (95\% CI 0.35-0.51) for an intake of 20,30, and $40 \mathrm{~g} /$ day, respectively, compared with $7.5 \mathrm{~g} /$ day (Fig. 2b, Supplementary Table 2).

\section{Types of fibre}

Four studies (three publications) [12, 17, 18] $(18,470$ cases, 818,796 participants), two studies [12, 17] $(17,710$ cases, 737,963 participants), and two studies [12, 17] $(17,710$ cases, 737,963 participants $)$ were included in the

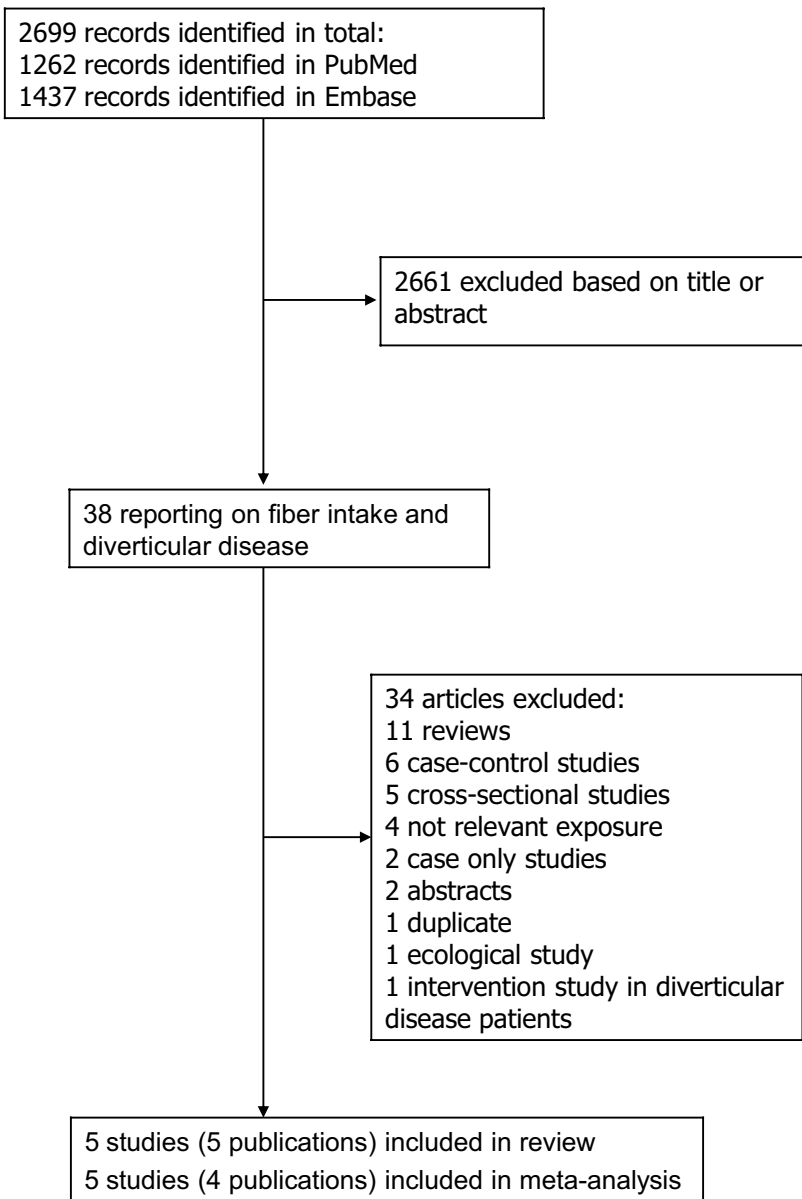

Fig. 1 Flow-chart of study selection of dietary fibre and diverticular disease

meta-analysis of cereal fibre, fruit fibre, and vegetable fibre and risk of diverticular disease, respectively. The summary RR per $10 \mathrm{~g} /$ day of intake was 0.74 (95\% CI 0.67-0.81, $I^{2}=60 \%, p_{\text {heterogeneity }}=0.06$ ) for cereal fibre intake (Fig. $3 \mathrm{a}$ ); however, the $95 \%$ PI did not exclude the null value, summary RR 0.74 (95\% PI 0.51-1.07). There was evidence of a nonlinear association between cereal fibre intake and diverticular disease risk $\left(p_{\text {nonlinearity }}=0.002\right)$, with a slight increase in risk at low levels of intake, but a reduced risk was observed from around $15 \mathrm{~g} /$ day up to $30 \mathrm{~g} /$ day (Fig. 3b). The summary RR was 0.56 (95\% CI $0.37-0.84, I^{2}=73 \%$, $p_{\text {heterogeneity }}=0.06$ ) per $10 \mathrm{~g} /$ day of fruit fibre (Fig. 3c) and $0.80\left(95 \%\right.$ CI $\left.0.45-1.44, I^{2}=87 \%, p_{\text {heterogeneity }}=0.10\right)$ for vegetable fibre (Fig. 3d).

\section{Subgroup and sensitivity analyses and study quality}

The inverse association between dietary fibre intake and diverticular disease persisted in a number of subgroup analyses defined by duration of follow-up, sex, geographic location, number of cases, study quality and adjustment 


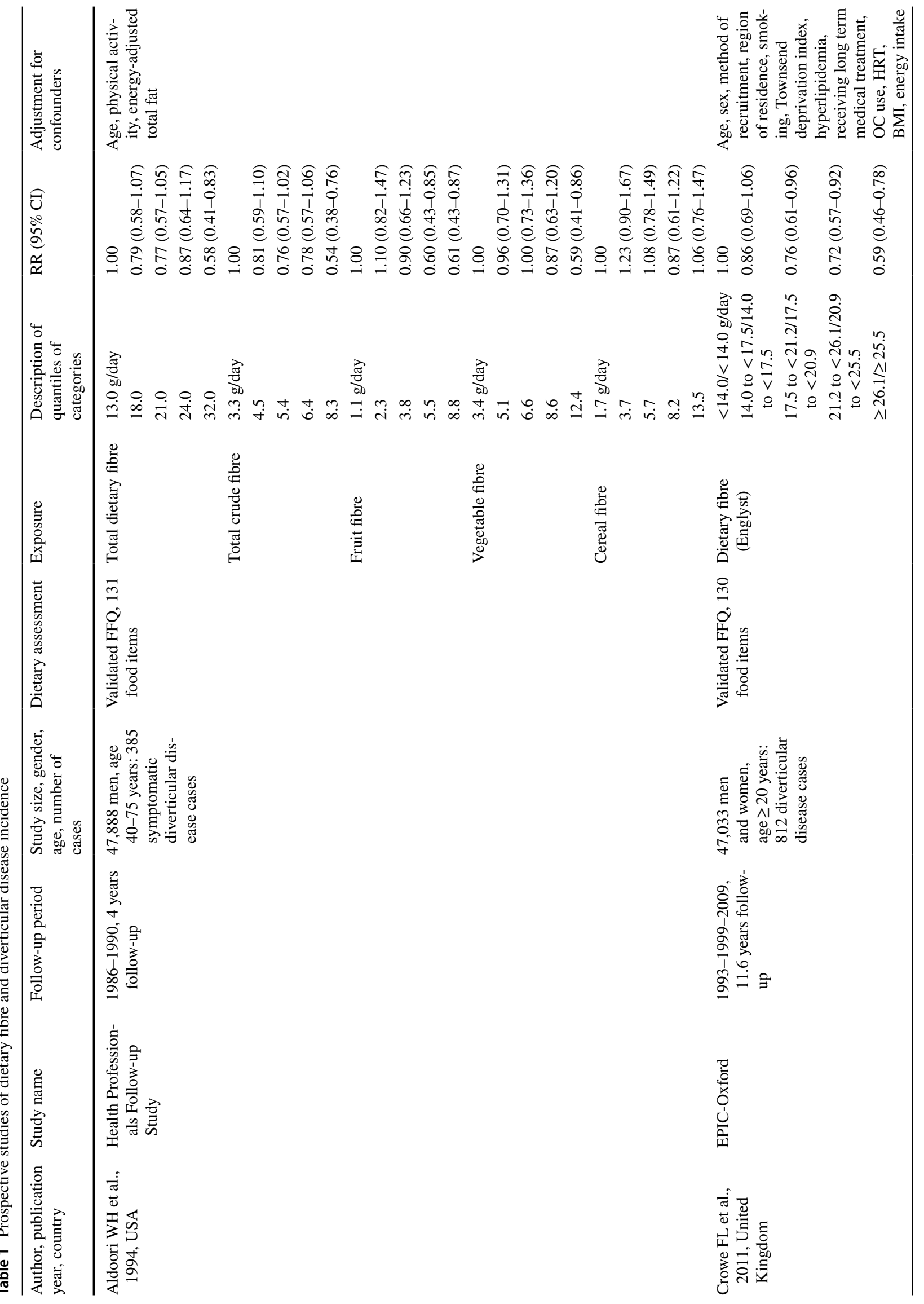




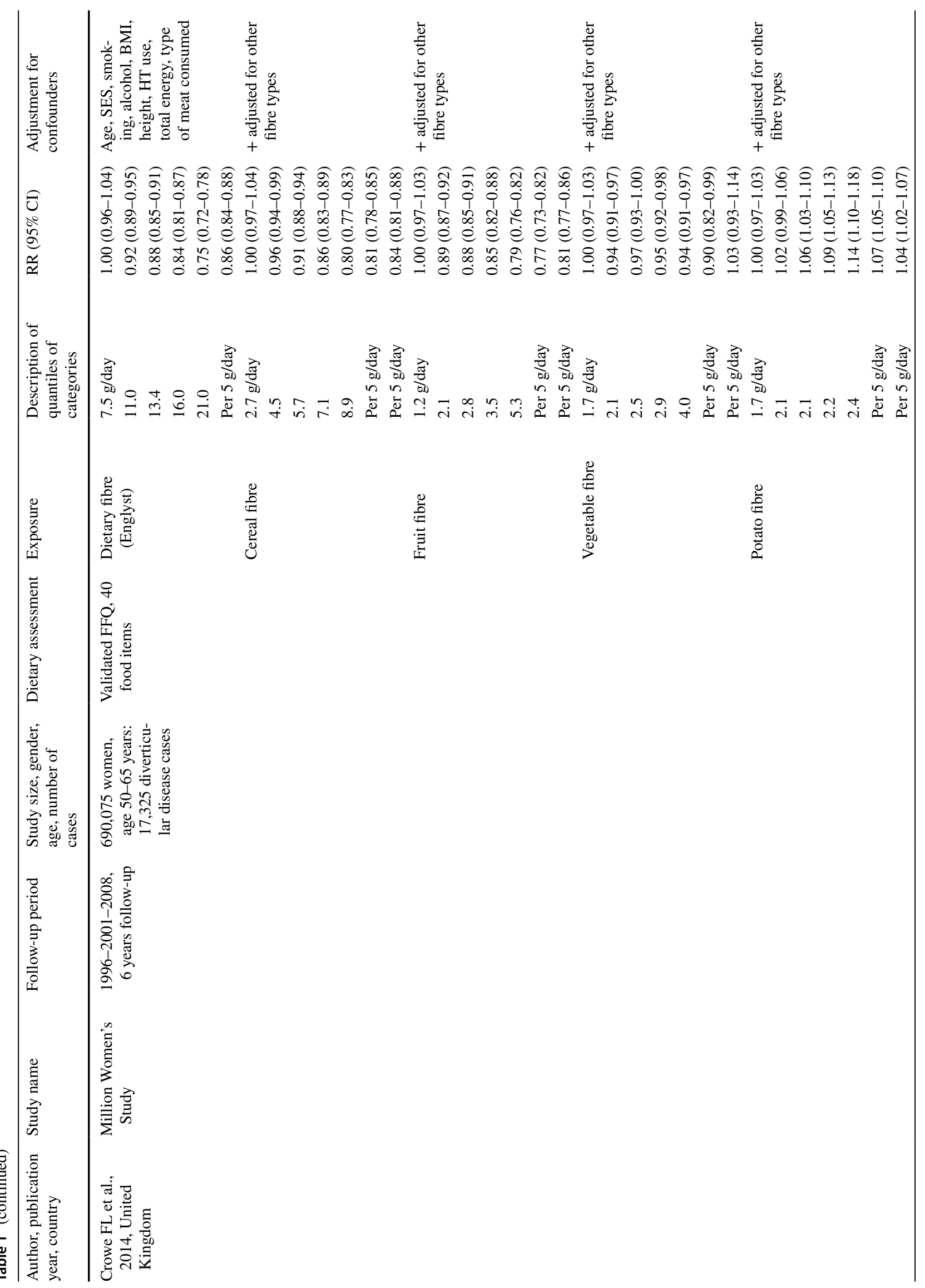




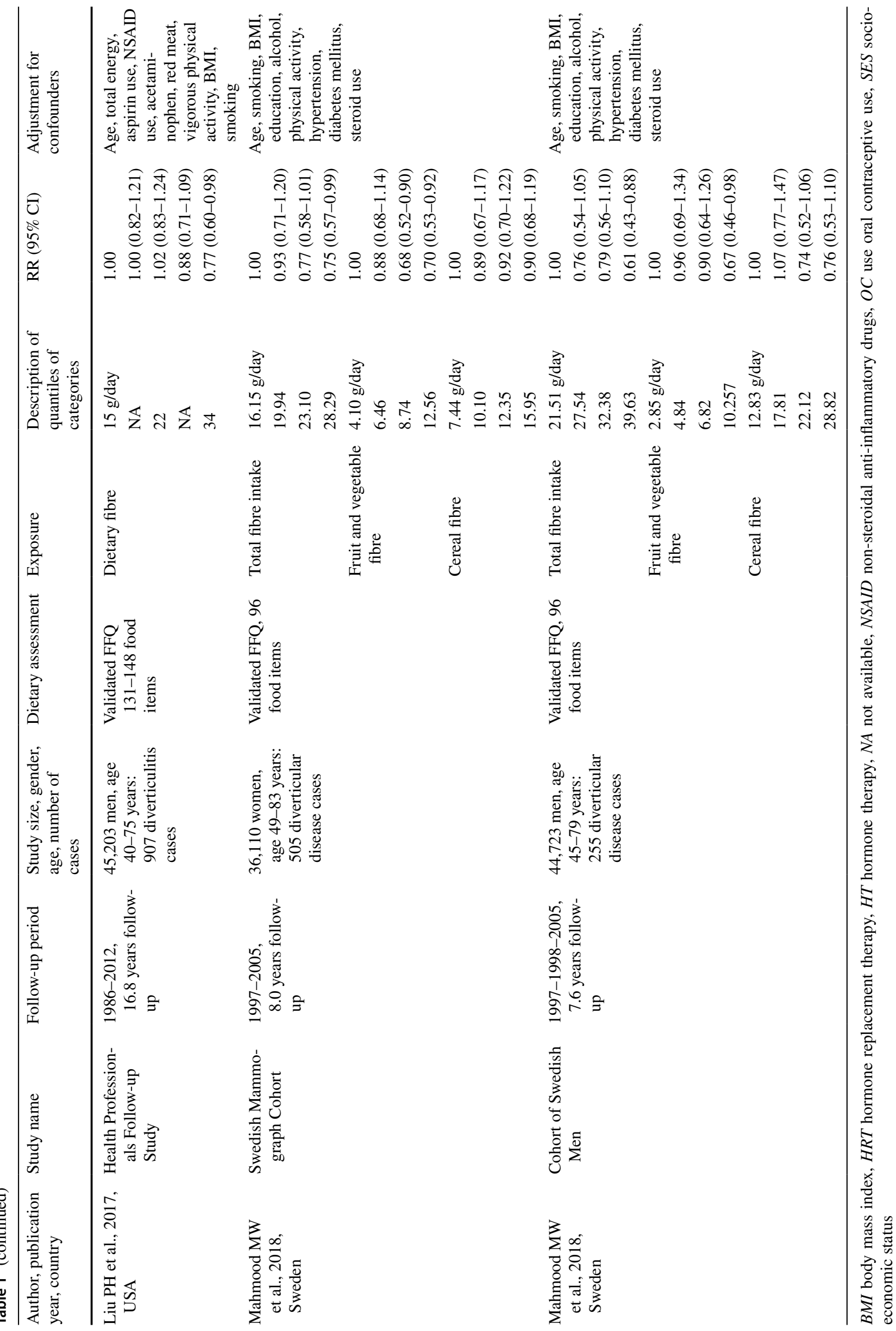


Fig. 2 Dietary fibre and diverticular disease incidence, linear dose-response analysis (per $10 \mathrm{~g} /$ day) and nonlinear doseresponse analysis

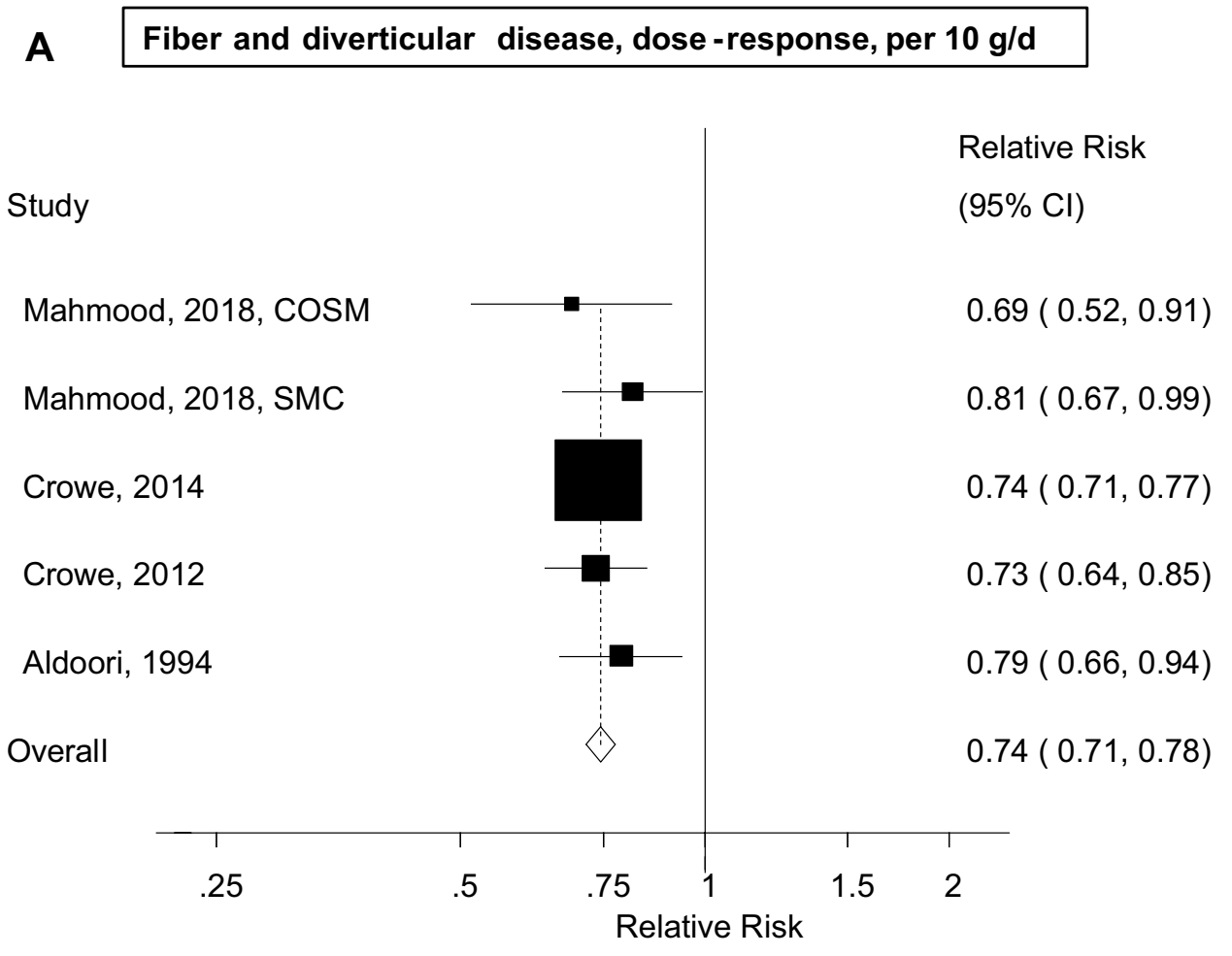

B Fiber and diverticular disease, nonlinear dose -response

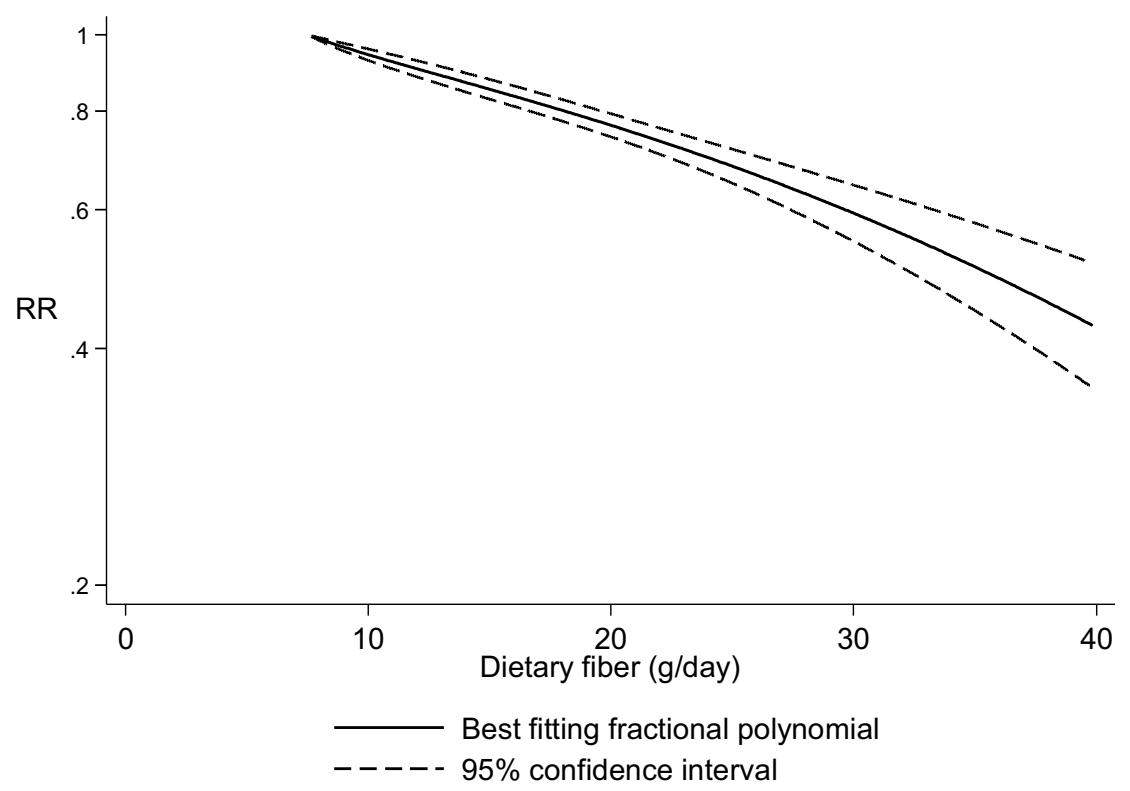

for potential confounding factors (including age, education, alcohol, smoking, BMI, physical activity, diabetes, meat intake, energy intake) (Table 2); however, no studies adjusted for aspirin or NSAID use. With meta-regression analyses, there was no indication of heterogeneity between any of the subgroup analyses.
We also repeated all analyses using fixed-effects models, but the results were in general similar with summary RRs of 0.74 (95\% CI 0.71-0.78) for dietary fibre, 0.71 (95\% CI $0.68-0.74$ ) for cereal fibre, 0.64 (95\% CI $0.57-0.71$ ) for fruit fibre and 0.93 (95\% CI 0.77-1.11) for vegetable fibre.

The mean (median) study quality scores were 8.0 (8.0) for the studies included in the analysis of dietary fibre and 


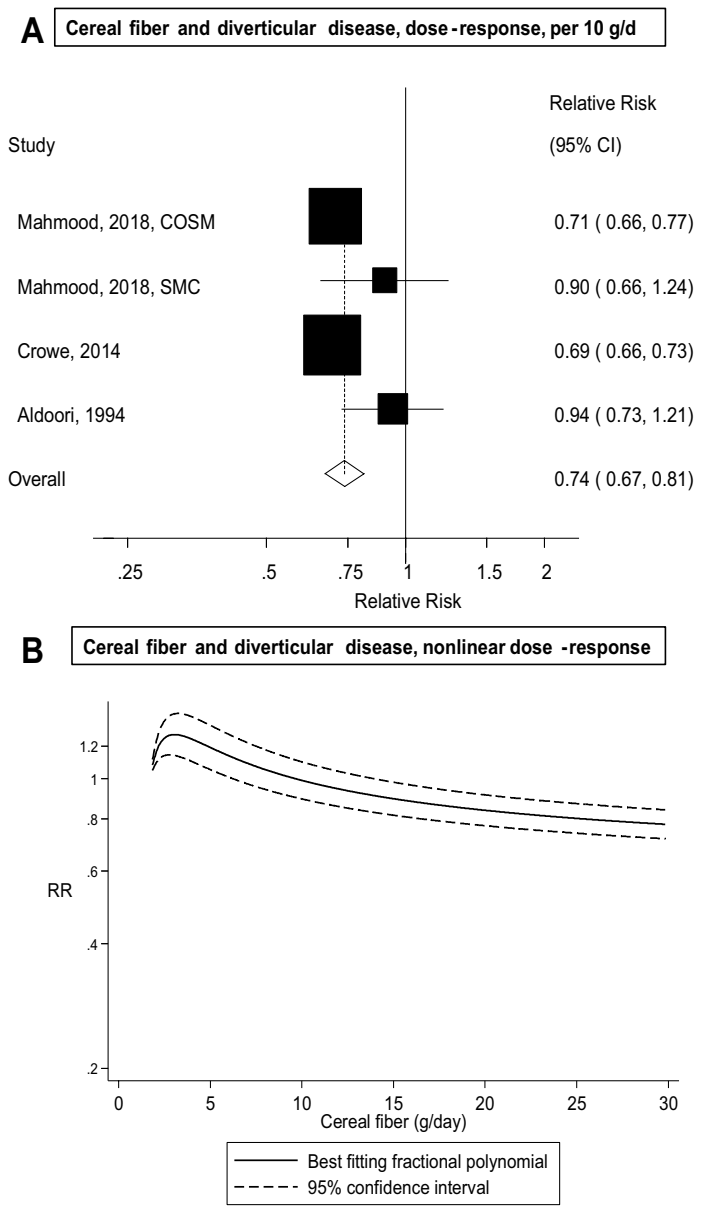

C

Fruit fiber and diverticular disease, dose-response, per $10 \mathrm{~g} / \mathrm{d}$

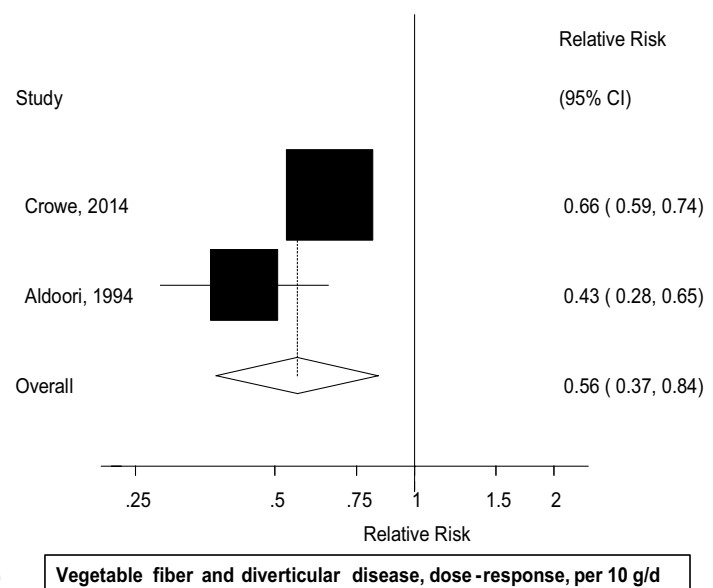

D

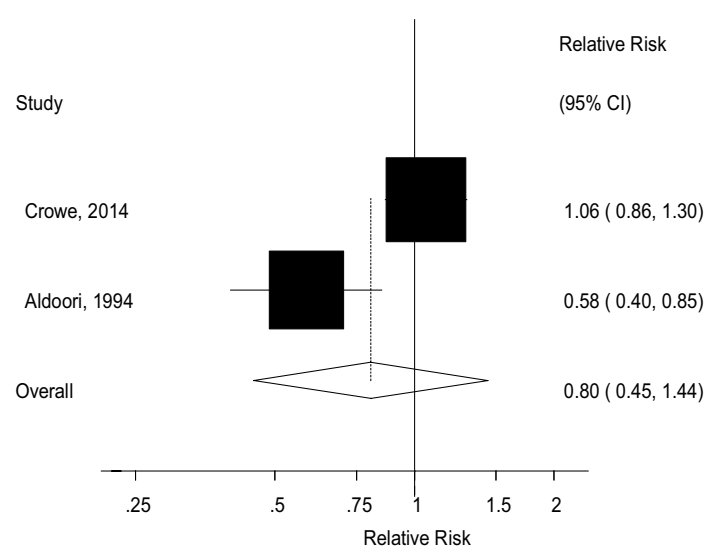

Fig. 3 Fibre types and diverticular disease, linear and nonlinear dose-response

diverticular disease risk. With regard to the study quality scores, studies had less than maximum scores because of not being representative of the general population (two studies) and because loss to follow-up was not reported (three studies) (Supplementary Table 3).

\section{Discussion}

This meta-analysis of five prospective studies with $>19,000$ cases and $>865,000$ participants suggest that a high intake of dietary fibre reduces the risk of developing diverticular disease. There was a $26 \%, 44 \%$, and $26 \%$ reduction in risk per $10 \mathrm{~g} /$ day of intake of total dietary fibre, fruit fibre, and cereal fibre, respectively. There was no evidence of nonlinearity in the analysis of overall fibre intake and risk was reduced by $58 \%$ with an intake of $40 \mathrm{~g} /$ day compared with $7.5 \mathrm{~g} /$ day. There was some evidence of nonlinearity in the analysis of cereal fibre intake, with a slight increase in risk at low levels of intake, but a reduced risk with an intake from 15 to $30 \mathrm{~g} /$ day.
Limitations of the present systematic review and metaanalysis include the possibility of confounding, heterogeneity between studies, measurement errors in the assessment of dietary fibre intake and regression dilution bias during follow-up, as well as potential publication biases. Individuals with a high fibre intake tend to have a healthier overall lifestyle than individuals with a low fibre intake, with a lower intake of meat, higher physical activity, less obesity and lower prevalence of smoking. However, the inverse association between fibre intake and diverticular disease was observed across all subgroup analyses stratified by sex, duration of follow-up, geographic location, number of cases and adjustment for confounding factors (age, education, alcohol, smoking, diabetes, BMI, physical activity, meat and energy intake) and there was no between-subgroup heterogeneity. In addition, in the Million Women's Study, the inverse association between dietary fibre intake and diverticular disease risk was observed across strata of age, socioeconomic status, smoking status, alcohol intake, BMI, height, hormone therapy use, consumption of red and processed meat, and persisted after excluding the first 3 years of follow-up (to 
Table 2 Subgroup analyses of fibre intake and diverticular disease

\begin{tabular}{|c|c|c|c|c|c|}
\hline & \multicolumn{5}{|c|}{ Fibre } \\
\hline & $n$ & RR $(95 \%$ CI $)$ & $I^{2}(\%)$ & $p_{\mathrm{h}}^{\mathrm{a}}$ & $p_{\mathrm{h}}^{\mathrm{b}}$ \\
\hline All studies & 5 & $0.74(0.71-0.78)$ & 0 & 0.80 & \\
\hline \multicolumn{6}{|l|}{ Sex } \\
\hline Men & 3 & $0.77(0.68-0.88)$ & 0 & 0.64 & \multirow[t]{3}{*}{0.61} \\
\hline Women & 3 & $0.74(0.71-0.78)$ & 0 & 0.62 & \\
\hline Men and women & 0 & & & & \\
\hline \multicolumn{6}{|l|}{ Assessment of diet } \\
\hline Validated & 5 & $0.74(0.71-0.78)$ & 0 & 0.80 & \multirow[t]{2}{*}{$\mathrm{NC}$} \\
\hline Not validated & 0 & & & & \\
\hline \multicolumn{6}{|l|}{ Duration of follow-up } \\
\hline$<10$ years follow-up & 4 & $0.74(0.71-0.78)$ & \multirow[t]{2}{*}{0} & 0.66 & \multirow[t]{2}{*}{0.87} \\
\hline$\geq 10$ years follow-up & 1 & $0.73(0.64-0.85)$ & & & \\
\hline \multicolumn{6}{|l|}{ Geographic location } \\
\hline Europe & 4 & $0.74(0.71-0.77)$ & \multirow[t]{3}{*}{0} & 0.76 & \multirow[t]{3}{*}{0.54} \\
\hline America & 1 & $0.79(0.66-0.94)$ & & & \\
\hline Asia & 0 & & & & \\
\hline \multicolumn{6}{|l|}{ Number of cases } \\
\hline Cases $<500$ & 2 & $0.76(0.65-0.88)$ & 0 & 0.41 & \multirow[t]{3}{*}{0.66} \\
\hline Cases $500<1000$ & 2 & $0.76(0.68-0.86)$ & 0 & 0.41 & \\
\hline Cases $\geq 1000$ & 1 & $0.74(071-0.77)$ & & & \\
\hline \multicolumn{6}{|l|}{ Study quality } \\
\hline $0-3$ points & 0 & & & & \multirow[t]{3}{*}{$\mathrm{NC}$} \\
\hline $4-6$ & 0 & & & & \\
\hline $7-9$ & 5 & $0.74(0.71-0.78)$ & 0 & 0.80 & \\
\hline \multicolumn{6}{|c|}{ Adjustment for confounders } \\
\hline \multicolumn{6}{|l|}{ Age } \\
\hline Yes & 5 & $0.74(0.71-0.78)$ & 0 & 0.80 & \multirow[t]{2}{*}{$\mathrm{NC}$} \\
\hline No & 0 & & & & \\
\hline \multicolumn{6}{|l|}{ Education } \\
\hline Yes & 2 & $0.77(0.65-0.91)$ & 0 & 0.33 & \multirow[t]{2}{*}{0.70} \\
\hline No & 3 & $0.74(0.71-0.77)$ & 0 & 0.77 & \\
\hline \multicolumn{6}{|l|}{ Alcohol } \\
\hline Yes & 3 & $0.74(0.71-0.78)$ & 0 & 0.56 & 0.77 \\
\hline No & 2 & $0.76(0.68-0.85)$ & 0 & 0.53 & \\
\hline Smoking & & & & & \\
\hline Yes & 4 & $0.74(0.71-0.77)$ & 0 & 0.76 & 0.54 \\
\hline No & 1 & $0.79(0.66-0.94)$ & & & \\
\hline Diabetes & & & & & \\
\hline Yes & 2 & $0.77(0.65-0.91)$ & 0 & 0.33 & 0.70 \\
\hline No & 3 & $0.74(0.71-0.77)$ & 0 & 0.77 & \\
\hline Aspirin use & & & & & \\
\hline Yes & 0 & & & & $\mathrm{NC}$ \\
\hline No & 5 & $0.74(0.71-0.78)$ & 0 & 0.80 & \\
\hline NSAID use & & & & & \\
\hline Yes & 0 & & & & $\mathrm{NC}$ \\
\hline No & 5 & $0.74(0.71-0.78)$ & 0 & 0.80 & \\
\hline Body mass index & & & & & \\
\hline Yes & 4 & $0.74(0.71-0.77)$ & 0 & 0.76 & 0.54 \\
\hline No & 1 & $0.79(0.66-0.94)$ & & & \\
\hline
\end{tabular}

Table 2 (continued)

\begin{tabular}{|c|c|c|c|c|c|}
\hline & \multicolumn{5}{|c|}{ Fibre } \\
\hline & $n$ & RR (95\% CI) & $I^{2}(\%)$ & $p_{\mathrm{h}}^{\mathrm{a}}$ & $p_{\mathrm{h}}^{\mathrm{b}}$ \\
\hline \multicolumn{6}{|c|}{ Physical activity } \\
\hline Yes & 3 & $0.78(0.69-0.88)$ & 0 & 0.61 & 0.48 \\
\hline No & 2 & $0.74(0.71-0.77)$ & 0 & 0.93 & \\
\hline \multicolumn{6}{|l|}{ Meat } \\
\hline Yes & 1 & $0.74(0.71-0.77)$ & & & 0.63 \\
\hline No & 4 & $0.76(0.69-0.83)$ & 0 & 0.71 & \\
\hline \multicolumn{6}{|c|}{ Energy } \\
\hline Yes & 2 & $0.74(0.71-0.77)$ & 0 & 0.93 & 0.48 \\
\hline No & 3 & $0.78(0.69-0.88)$ & 0 & 0.61 & \\
\hline
\end{tabular}

reduce the potential for reverse causation) [17]. Nevertheless, residual confounding or confounding by other risk factors cannot be completely excluded. In the analysis of dietary fibre intake, there was no evidence of heterogeneity between studies, but there was some evidence of heterogeneity in the analyses of fruit, vegetable and cereal fibre intake. This appeared to be mainly due to differences between studies in the strength of the association between different fibre types and diverticular disease risk. This is less problematic than if there were differences in the direction of the observed effect between studies.

Measurement errors in the assessment of dietary fibre intake may have affected the observed results; however, none of the included studies made corrections for measurement error. Nevertheless, all studies used validated the food frequency questionnaires and in the Nurses' Health Study and Health Professionals Follow-up Study, the correlations with fibre intakes estimated from food records were in the range of 0.51-0.58 [29, 30] and in the Swedish Mammography Cohort, the correlation between the FFQ and diet records was $0.4-0.7$ for foods high in fibre (fruits, vegetables, whole grains) [18] and 0.71 for dietary fibre [31]. The participants may also have changed their intake of dietary fibre during follow-up; however, the studies included used a baseline dietary assessment for the analyses of dietary fibre intake and diverticular disease risk (although some of the studies may have repeated measures of dietary intake, but may not have utilised this either because of short follow-up or other reasons). However, both measurement errors and changes in diet during follow-up would most likely have led to attenuation of the relative risks given the prospective design of the studies.

A further limitation is that most of the primary studies identified diverticular disease cases by linkage to hospital 
databases and death registries [16-18]. One study identified symptomatic diverticular disease cases by self-report which then was validated against medical records and found 95\% agreement between the two methods [32]. Most of the cases in these studies would, therefore, have been symptomatic and represent more severe disease, while it is known that many cases can be asymptomatic or only have mild symptoms. If people with a low fibre intake were more likely to be admitted to hospital and undergo examinations for symptoms like constipation, it is possible that detection bias partly could explain the observed association. However, in the Million Women's Study, the association was similar among people with and without constipation and the association persisted also among participants without comorbidity [17]. Although publication bias can affect the results of meta-analyses of published studies, we found no evidence of such bias in this meta-analysis.

Several mechanisms may explain the inverse association between dietary fibre intake and the risk of diverticular disease. A high intake of dietary fibre is associated with increased stool bulk and reduced transit time [33-35] and may require less pressure during defecation, and may therefore reduce the possibility for the mucosa to herniate through the weak areas in the colon [1]. Bacterial fermentation of dietary fibre produces short-chain fatty acids (e.g. butyrate) which are a fuel source for the colonic cells [35]. Several animal studies have shown that a low-fibre diet substantially increases the rates for colonic diverticula [36-39]. Some studies have suggested differences in the gut microbiota of diverticular disease patients compared to controls [40-45] and one study suggested that patients with diverticular disease have depletion of microbiota with anti-inflammatory activity [40]. Further studies are needed to clarify whether and how fibre intake might interact with the microbiota in reducing diverticular disease risk. Dietary fibre is also associated with less adiposity and lower risk of overweight and obesity [46, 47] and could, therefore, reduce the risk of diverticular disease indirectly, since overweight and obesity increase the risk [9]. However, most of the studies included in this analysis adjusted for BMI; thus, it seems that the observed association is largely independent of adiposity.

The present meta-analysis has several strengths including the prospective design of the studies (which avoids recall bias and reduces the potential for selection bias), the detailed subgroup, sensitivity, and dose-response analyses, the relatively large sample size providing a robust estimate of the association between dietary fibre and diverticular disease, as well as the high study quality of the included studies. Our findings have important clinical and public health implications as the inverse association between fibre intake and diverticular disease was rather strong and dose dependent with a $41 \%$ reduction in risk at an intake of $30 \mathrm{~g} /$ day (compared to $7.5 \mathrm{~g} /$ day) and because the mean fibre intake in many populations is only around $13-25 \mathrm{~g} /$ day $[48,49]$. The current findings are consistent with other studies showing benefits of a high fibre intake in relation to breast cancer [50], colorectal cancer [14], type 2 diabetes [51] and mortality [52], but provide further evidence of an association also with diverticular disease. Any future studies should further clarify the association between different sources of fibre and risk of diverticular disease as well as diverticulitis.

In conclusion, this meta-analysis found a strong and linear reduction in risk of diverticular disease with a high dietary fibre intake up to an intake of $40 \mathrm{~g} /$ day. Fibre from cereals and fruit were associated with reduced risk, but further studies are needed on fibre types given the limited number of studies. These results support public health recommendations to increase the intake of dietary fibre in the general population.

Author contributions DA had full access to all of the data and takes responsibility for the integrity of the data and the accuracy of the data analysis. DA and AS are guarantors for the study. Study concept and design: DA, AS, TN, ER. Acquisition, analysis or interpretation of data: DA, AS, TN, ER. Checking of data extraction: AS. Drafting of manuscript: DA. Critical revision of the manuscript for important intellectual content: DA, AS, TN, ER. Statistical analysis: DA. Obtaining funding: DA, AS, ER. Study supervision: TN.

Funding This work has been supported by funding from the School of Public Health, Imperial College London and the South-East Regional Health Authorities of Norway. The funders had no role in the study design, data collection, data analysis and interpretation, writing of the report, or the decision to submit the article for publication.

\section{Compliance with ethical standards}

Conflict of interest The authors declare that there are no conflicts of interest.

Open Access This article is distributed under the terms of the Creative Commons Attribution 4.0 International License (http://creativeco mmons.org/licenses/by/4.0/), which permits unrestricted use, distribution, and reproduction in any medium, provided you give appropriate credit to the original author(s) and the source, provide a link to the Creative Commons license, and indicate if changes were made.

\section{References}

1. Painter NS, Burkitt DP (1971) Diverticular disease of the colon: a deficiency disease of Western civilization. Br Med J 2:450-454

2. Kyle J, Adesola AO, Tinckler LF, de Beaux J (1967) Incidence of diverticulitis. Scand J Gastroenterol 2:77-80

3. Nakaji S, Danjo K, Munakata A, Sugawara K, MacAuley D, Kernohan G, Baxter D (2002) Comparison of etiology of right-sided diverticula in Japan with that of left-sided diverticula in the West. Int J Colorectal Dis 17:365-373 
4. Munakata A, Nakaji S, Takami H, Nakajima H, Iwane S, Tuchida S (1993) Epidemiological evaluation of colonic diverticulosis and dietary fiber in Japan. Tohoku J Exp Med 171:145-151

5. Stemmermann GN, Mandel M, Mower HF (1979) Colon cancer: its precursors and companions in Hawaii Japanese. Natl Cancer Inst Monogr 53:175-179

6. Hjern F, Johansson C, Mellgren A, Baxter NN, Hjern A (2006) Diverticular disease and migration-the influence of acculturation to a Western lifestyle on diverticular disease. Aliment Pharmacol Ther 23:797-805

7. Horner JL (1958) Natural history of diverticulosis of the colon. Am J Dig Dis 3:343-350

8. Welch CE, Allen AW, Donaldson GA (1953) An appraisal of resection of the colon for diverticulitis of the sigmoid. Ann Surg 138:332-343

9. Aune D, Sen A, Leitzmann MF, Norat T, Tonstad S, Vatten LJ (2017) Body mass index and physical activity and the risk of diverticular disease: a systematic review and meta-analysis of prospective studies. Eur J Nutr 56:2423-2438

10. Aune D, Sen A, Leitzmann MF, Tonstad S, Norat T, Vatten LJ (2017) Tobacco smoking and the risk of diverticular diseasea systematic review and meta-analysis of prospective studies. Colorectal Dis 19:621-633

11. Aldoori WH, Giovannucci EL, Rimm EB, Wing AL, Willett WC (1998) Use of acetaminophen and nonsteroidal anti-inflammatory drugs: a prospective study and the risk of symptomatic diverticular disease in men. Arch Fam Med 7:255-260

12. Aldoori WH, Giovannucci EL, Rimm EB, Wing AL, Trichopoulos DV, Willett WC (1994) A prospective study of diet and the risk of symptomatic diverticular disease in men. Am J Clin Nutr 60:757-764

13. Ben Q, Sun Y, Chai R, Qian A, Xu B, Yuan Y (2014) Dietary fiber intake reduces risk for colorectal adenoma: a meta-analysis. Gastroenterology 146:689-699

14. Aune D, Chan DS, Lau R, Vieira R, Greenwood DC, Kampman E, Norat T (2011) Dietary fibre, whole grains, and risk of colorectal cancer: systematic review and dose-response metaanalysis of prospective studies. BMJ 343:d6617

15. Ananthakrishnan AN, Khalili H, Konijeti GG, Higuchi LM, de Silva P, Korzenik JR, Fuchs CS, Willett WC, Richter JM, Chan AT (2013) A prospective study of long-term intake of dietary fiber and risk of Crohn's disease and ulcerative colitis. Gastroenterology 145:970-977

16. Crowe FL, Appleby PN, Allen NE, Key TJ (2011) Diet and risk of diverticular disease in Oxford cohort of European Prospective Investigation into Cancer and Nutrition (EPIC): prospective study of British vegetarians and non-vegetarians. BMJ 343: $\mathrm{d} 4131$

17. Crowe FL, Balkwill A, Cairns BJ, Appleby PN, Green J, Reeves GK, Key TJ, Beral V (2014) Source of dietary fibre and diverticular disease incidence: a prospective study of UK women. Gut 63:1450-1456

18. Mahmood MW, Braham-Nordling M, Hakansson N, Wolk A, Hjern F (2018) High intake of dietary fibre from fruit and vegetables reduces the risk of hospitalisation for diverticular disease. Eur J Nutr. https://doi.org/10.1007/s00394-018-1792-0

19. Stroup DF, Berlin JA, Morton SC, Olkin I, Williamson GD, Rennie D, Moher D, Becker BJ, Sipe TA, Thacker SB (2000) Metaanalysis of observational studies in epidemiology: a proposal for reporting. Meta-analysis of observational studies in epidemiology (MOOSE) group. JAMA 283:2008-2012

20. DerSimonian R, Laird N (1986) Meta-analysis in clinical trials. Control Clin Trials 7:177-188

21. Greenland S, Longnecker MP (1992) Methods for trend estimation from summarized dose-response data, with applications to metaanalysis. Am J Epidemiol 135:1301-1309
22. Royston P (2000) A strategy for modelling the effect of a continuous covariate in medicine and epidemiology. Stat Med 19:1831-1847

23. Bagnardi V, Zambon A, Quatto P, Corrao G (2004) Flexible metaregression functions for modeling aggregate dose-response data, with an application to alcohol and mortality. Am J Epidemiol 159:1077-1086

24. Higgins JP, Thompson SG (2002) Quantifying heterogeneity in a meta-analysis. Stat Med 21:1539-1558

25. Wells G, Shea B, O'Connell D., Peterson J, Welch V, Losos M, Tugwell P (2013) The Newcastle-Ottawa Scale (NOS) for assessing the quality of nonrandomised studies in meta-analyses. http://www.ohri.ca/programs/clinical_epidemiology/oxford.asp. Accessed 09 Aug 2018

26. Egger M, Davey SG, Schneider M, Minder C (1997) Bias in metaanalysis detected by a simple, graphical test. BMJ 315:629-634

27. Begg CB, Mazumdar M (1994) Operating characteristics of a rank correlation test for publication bias. Biometrics 50:1088-1101

28. Liu PH, Cao Y, Keeley BR, Tam I, Wu K, Strate LL, Giovannucci EL, Chan AT (2017) Adherence to a healthy lifestyle is associated with a lower risk of diverticulitis among men. Am J Gastroenterol 112:1868-1876

29. Willett WC, Sampson L, Stampfer MJ, Rosner B, Bain C, Witschi J, Hennekens CH, Speizer FE (1985) Reproducibility and validity of a semiquantitative food frequency questionnaire. Am J Epidemiol 122:51-65

30. Rimm EB, Giovannucci EL, Stampfer MJ, Colditz GA, Litin LB, Willett WC (1992) Reproducibility and validity of an expanded self-administered semiquantitative food frequency questionnaire among male health professionals. Am J Epidemiol 135:1114-1126

31. Messerer M, Johansson SE, Wolk A (2004) The validity of questionnaire-based micronutrient intake estimates is increased by including dietary supplement use in Swedish men. J Nutr 134:1800-1805

32. Aldoori WH, Giovannucci EL, Rockett HR, Sampson L, Rimm EB, Willett WC (1998) A prospective study of dietary fiber types and symptomatic diverticular disease in men. J Nutr 128:714-719

33. Wrick KL, Robertson JB, Van Soest PJ, Lewis BA, Rivers JM, Roe DA, Hackler LR (1983) The influence of dietary fiber source on human intestinal transit and stool output. J Nutr 113:1464-1479

34. Hillemeier C (1995) An overview of the effects of dietary fiber on gastrointestinal transit. Pediatrics 96:997-999

35. Lipkin M, Reddy B, Newmark H, Lamprecht SA (1999) Dietary factors in human colorectal cancer. Annu Rev Nutr 19:545-586

36. Fisher N, Berry CS, Fearn T, Gregory JA, Hardy J (1985) Cereal dietary fiber consumption and diverticular disease: a lifespan study in rats. Am J Clin Nutr 42:788-804

37. Jaskiewicz K, Rossouw JE, Kritchevsky D, van Rensburg SJ, Fincham JE, Woodroof CW (1986) The influence of diet and dimethylhydrazine on the small and large intestine of vervet monkeys. $\mathrm{Br}$ J Exp Pathol 67:361-369

38. Wess L, Eastwood MA, Edwards CA, Busuttil A, Miller A (1996) Collagen alteration in an animal model of colonic diverticulosis. Gut 38:701-706

39. Wess L, Eastwood M, Busuttil A, Edwards C, Miller A (1996) An association between maternal diet and colonic diverticulosis in an animal model. Gut 39:423-427

40. Barbara G, Scaioli E, Barbaro MR, Biagi E, Laghi L, Cremon C, Marasco G, Colecchia A, Picone G, Salfi N, Capozzi F, Brigidi P, Festi D (2017) Gut microbiota, metabolome and immune signatures in patients with uncomplicated diverticular disease. Gut 66:1252-1261

41. Daniels L, Budding AE, de Korte N, Eck A, Bogaards JA, Stockmann HB, Consten EC, Savelkoul PH, Boermeester MA (2014) Fecal microbiome analysis as a diagnostic test for diverticulitis. Eur J Clin Microbiol Infect Dis 33:1927-1936 
42. Tursi A, Mastromarino P, Capobianco D, Elisei W, Miccheli A, Capuani G, Tomassini A, Campagna G, Picchio M, Giorgetti G, Fabiocchi F, Brandimarte G (2016) Assessment of fecal microbiota and fecal metabolome in symptomatic uncomplicated diverticular disease of the colon. J Clin Gastroenterol 50(Suppl 1):S9-S12

43. Lopetuso LR, Petito V, Graziani C, Schiavoni E, Paroni SF, Poscia A, Gaetani E, Franceschi F, Cammarota G, Sanguinetti M, Masucci L, Scaldaferri F, Gasbarrini A (2018) Gut microbiota in health, diverticular disease, irritable bowel syndrome, and inflammatory bowel diseases: time for microbial marker of gastrointestinal disorders. Dig Dis 36:56-65

44. Kvasnovsky CL, Leong LEX, Choo JM, Abell GCJ, Papagrigoriadis S, Bruce KD, Rogers GB (2018) Clinical and symptom scores are significantly correlated with fecal microbiota features in patients with symptomatic uncomplicated diverticular disease: a pilot study. Eur J Gastroenterol Hepatol 30:107-112

45. Linninge C, Roth B, Erlanson-Albertsson C, Molin G, Toth E, Ohlsson B (2018) Abundance of Enterobacteriaceae in the colon mucosa in diverticular disease. World J Gastrointest Pathophysiol 9:18-27

46. Koh-Banerjee P, Franz M, Sampson L, Liu S, Jacobs DR Jr, Spiegelman D, Willett W, Rimm E (2004) Changes in wholegrain, bran, and cereal fiber consumption in relation to 8-y weight gain among men. Am J Clin Nutr 80:1237-1245

47. Liu S, Willett WC, Manson JE, Hu FB, Rosner B, Colditz G (2003) Relation between changes in intakes of dietary fiber and grain products and changes in weight and development of obesity among middle-aged women. Am J Clin Nutr 78:920-927

48. Bingham SA, Day NE, Luben R, Ferrari P, Slimani N, Norat T, Clavel-Chapelon F, Kesse E, Nieters A, Boeing H, Tjonneland A, Overvad K, Martinez C, Dorronsoro M, Gonzalez CA, Key TJ, Trichopoulou A, Naska A, Vineis P, Tumino R, Krogh V,
Bueno-de-Mesquita HB, Peeters PH, Berglund G, Hallmans G, Lund E, Skeie G, Kaaks R, Riboli E (2003) Dietary fibre in food and protection against colorectal cancer in the European Prospective Investigation into Cancer and Nutrition (EPIC): an observational study. Lancet 361:1496-1501

49. Park Y, Hunter DJ, Spiegelman D, Bergkvist L, Berrino F, van den Brandt PA, Buring JE, Colditz GA, Freudenheim JL, Fuchs CS, Giovannucci E, Goldbohm RA, Graham S, Harnack L, Hartman AM, Jacobs DR Jr, Kato I, Krogh V, Leitzmann MF, McCullough ML, Miller AB, Pietinen P, Rohan TE, Schatzkin A, Willett WC, Wolk A, Zeleniuch-Jacquotte A, Zhang SM, Smith-Warner SA (2005) Dietary fiber intake and risk of colorectal cancer: a pooled analysis of prospective cohort studies. JAMA 294:2849-2857

50. Aune D, Chan DS, Greenwood DC, Vieira AR, Rosenblatt DA, Vieira R, Norat T (2012) Dietary fiber and breast cancer risk: a systematic review and meta-analysis of prospective studies. Ann Oncol 23:1394-1402

51. The InterAct Consortium (2015) Dietary fibre and incidence of type 2 diabetes in eight European countries: the EPIC-InterAct Study and a meta-analysis of prospective studies. Diabetologia 58:1394-1408

52. Chuang SC, Norat T, Murphy N, Olsen A, Tjonneland A, Overvad K, Boutron-Ruault MC, Perquier F, Dartois L, Kaaks R, Teucher B, Bergmann MM, Boeing H, Trichopoulou A, Lagiou P, Trichopoulos D, Grioni S, Sacerdote C, Panico S, Palli D, Tumino R, Peeters PH, Bueno-de-Mesquita B, Ros MM, Brustad M, Asli LA, Skeie G, Quiros JR, Gonzalez CA, Sanchez MJ, Navarro C, Ardanaz AE, Dorronsoro M, Drake I, Sonestedt E, Johansson I, Hallmans G, Key T, Crowe F, Khaw KT, Wareham N, Ferrari P, Slimani N, Romieu I, Gallo V, Riboli E, Vineis P (2012) Fiber intake and total and cause-specific mortality in the European Prospective Investigation into Cancer and Nutrition cohort. Am J Clin Nutr 96:164-174 